\title{
Carbon Paste Electrode Modified by Multiwalled Carbon Nanotube "for Electrochemical Determination" of Vitamin C
}

\author{
M. Khodari*, E. M. Rabie, A. A. Shamroukh \\ Chemistry Department, Faculty of Science, South Valley University, Qena, Egypt
}

Copyright $@ 2018$ by authors, all rights reserved. Authors agree that this article remains permanently open access under the terms of the Creative Commons Attribution License 4.0 International License

\begin{abstract}
Carbon Paste Electrode Modified by silica gel /MWCNTs was manufactured and used for the electrochemical determination of Ascorbic acid (AA) in acetate buffer $(\mathrm{pH}=5.0)$ using cyclic, linear sweep voltammetry and square wave voltammetry $(\mathrm{CV}, \mathrm{LSV}$, and SWV). The results illustrated that the carbon paste modified electrode give a good response for an electrocatalytic activity toward the oxidation of AA. The electrochemical oxidation of AA at modified carbon paste electrode was diffusion-controlled and irreversible, using the optimum conditions to achieve the lower detection limit $1.07 \times 10^{-8} \mathrm{M}$, good reproducibility, and high stability. This method has been applied to the determination of AA in orange and lemon fruits, and the recoveries were from $96 \%$ to $102 \%$.
\end{abstract}

Keywords Silica Gel, MWCNTs, Modified Carbon Paste Electrode, Ascorbic Acid, Square-wave Voltammetry

\section{Introduction}

L-Ascorbic acid (vitamin C) is an important growth regulator as well as antioxidant for plants [1] where AA preventing plants from reactive oxygen species damage, cofactor of many enzymes, regulating cell division, cell expansion, cell wall metabolism, root development, photosynthesis, leaf senescence, hormones biosynthesis such as ethylene, gibberellins (GA) and abscisic acid (ABA) [2], abiotic and biotic stress, and flowering time [3-5]. Also, AA can function as a precursor for the biosynthesis of oxalic and L-tartaric acid in certain plants [6] so AA is as essential to plants as it is to animals [5], and thus it's very important to determine the concentration of AA in plants. It is so difficult to determine AA directly at ordinary electrodes, due to its high overpotential and consequent fouling by oxidation products [7]. So, many of chemically modified electrodes with various active mediators immobilized on the electrode surface have been used as the catalyst of electro-oxidation of AA [8-15].

Carbon paste electrodes have been widely applied in electrochemistry because of their advantages over membrane electrodes such as ease and speed of preparation, renewability, stable response, porous surface, low cost, low ohmic resistance [16-19]. Usually, the carbon paste consists of graphite powder dispersed in a nonconductive mineral oil. Recently, carbon nanotubes (CNTs) have been used in the modification of carbon paste electrodes mainly due to their very interesting physicochemical properties, such as ordered structure with high aspect ratio, ultra-lightweight, high mechanical strength, high electrical conductivity, high thermal conductivity, metallic or semi-metallic behavior and high surface area [20-22].

Silica gel is an inexpensive material which possesses some excellent properties such as high surface area, strong adsorption ability, high thermal stability and easy surface modification. Using of silica gel as a modifier in CPEs has many functional groups to enrichment the surface properties [23-25].

The aim of this study was to modify the CPE with Silica gel/CNTs and to use such an Electrode for the voltammetric determination of AA. We tested various conditions to find the optimal ones and tested to show the ability of an electrode to be used for determination of AA in fruits samples as a plant growth regulator.

\section{Experimental}

\subsection{Reagents}

Graphite powder, silica gel, hydrochloric acid, sodium hydroxide, sodium acetate, sodium dihydrogen phosphate, ortho and metaphosphoric acid, potassium and sodium 
chlorides, and all other chemicals were of analytical reagent grade from Merck. MWCNTs (length, 10-20 $\mu$ m, outside diameter, $450 \mathrm{~nm}$, inside diameter, $5-15 \mathrm{~nm}$ ) and standard AA were purchased from (Sigma-Aldrich). Its stock solution was prepared in deionized water. The experiment working solutions were prepared by diluting the stock solution with a selected supporting electrolyte. Four different supporting electrolytes, namely $\mathrm{KCl}(0.1 \mathrm{M})$, acetate buffer (0.1M, pH 4.7), Britton-Robinson buffer $(0.1$ $\mathrm{M}, \mathrm{pH}$ 2-9), and phosphate buffer (0.1M, pH 2.5 and 7.4) solutions were used.

All stock solutions were preserved at $4^{\circ} \mathrm{C}$ when not in use and protected from daylight during use in the laboratory. All other chemicals were of analytical grade and were used without further purification. Aqueous solutions were prepared with deionized water further purified via a Milli-Q unit (Millipore).

\subsection{Apparatus}

A VersaSTAT 4 (potentiostat/galvanostat) Princeton Applied Research, 305 magnetic stirrer (PARC). Electroanalytical software model 270 / 250 version 4.0 (PARC) control the potentiostat via IEEE 488 GPIB using IBM compatible 386 with VGA monitor. The characteristic of modern stripping analyzer potentiostat control of working electrode, which minimize errors from the cell resistance (distorted voltammogram with decreased peak current and shifted and broadened peaks). This is accomplished with a three-electrode system, the working electrode which is carbon paste electrode modified by silica gel nanoparticles/MWCNTs electrode, the reference electrode $(\mathrm{Ag} / \mathrm{AgCl})$ and a Pt wire as a counter electrode.

\subsection{Preparation of Carbon Paste Electrode Modified by Silica gel/CNTs}

The modified electrode is prepared by mixing $60 \%$ of pure graphite $(99.9 \%)$ with $(10 \%$ of MWCNTs $+5 \%$ Silica gel) in the presence of $25 \%$ from paraffin wax as a binder. The mixer is heated and then packing in a Teflon tube with $2 \mathrm{~mm}$ diameter. Finally, a copper wire is immersed in the paste to contact the cell. To activate the electrode surface, cyclic voltammograms were recorded in phosphate buffer solution $(\mathrm{pH}=5)$ between $0 \mathrm{~V}$ to $1.0 \mathrm{~V}$ until a steady voltammogram was obtained. By recording the current-voltage curve at different scan rates the active area of the electrode was obtained by cyclic voltammetric (CV) method using $1.0 \mathrm{mM} \mathrm{K}_{3} \mathrm{Fe}(\mathrm{CN})_{6}$ in $0.1 \mathrm{M} \mathrm{KCl}$. For a reversible process, the following Randles-Sevcik formula was used [26].

$$
\mathrm{Ip}=\left(2.69 \times 10^{5}\right) \mathrm{n}^{3 / 2} \mathrm{AD}_{\mathrm{R}}{ }^{0.5} v^{0.5} \mathrm{C}_{\mathrm{o}}
$$

where Ip refers to the anodic peak current, $\mathrm{n}$ is the number of electrons transferred, $\mathrm{A}$ is the surface area of the electrode, $D_{R}$ is the diffusion coefficient, $v$ is the scan rate and $\mathrm{Co}$ is the concentration of $\mathrm{K}_{3} \mathrm{Fe}(\mathrm{CN})_{6}$. For $1.0 \mathrm{mM}$ $\mathrm{K}_{3} \mathrm{Fe}(\mathrm{CN})_{6}$ in $0.1 \mathrm{M} \mathrm{KCl}$ electrolyte, $n=1, D_{R}=\left(7.6 \times 10^{-6}\right.$ $\mathrm{cm}^{2} / \mathrm{s}$ ), then the electroactive area was calculated from the slope of the plot of Ip versus $v 0.5$, relation and found to be $0.062 \mathrm{~cm}^{2}$.

\subsection{Extraction of Ascorbic Acid from Orange and Lemon Fruit Samples}

Extraction of AA from orange and lemon fruits samples was carried out as described previously [27]. Were About $100 \mathrm{~g}$ of fruits samples were separately weighed and dried under mild temperature $\left(15-20^{\circ} \mathrm{C}\right)$ and ground to fine powder dust before extraction. Then $1.0 \mathrm{~g}$ of obtained powder were weighed and subsequently extracted with $25 \mathrm{~mL}$ of extractant solution, containing $5 \%$ metaphosphoric acid (MPA), at $10^{\circ} \mathrm{C}$ and in the dark. The extraction process was performed using a shaker for $4 \mathrm{~h}$. All extractions were carried out in triplicate and obtained solutions were then filtered and stored at $4^{\circ} \mathrm{C}$ before less than $1 \mathrm{~h}$ before analysis.

\section{Results and Discussions}

\subsection{Cyclic Voltammetry (CV)}

Typical cyclic voltammograms of $2 \times 10^{-5} \mathrm{M}$ of AA obtained with Silica gel_MWCNTs/CPE in acetate buffer $(\mathrm{pH}=5.0)$ has been shown in Figure 1. As it is shown only one oxidation peak was observed at about $0.5 \mathrm{~V}$ and no reduction peak was observed on reverse scan what means that this redox reaction is totally irreversible. As observed, the anodic current peak increases about $0.21 \mu \mathrm{A}$ by the modification with silica gel while the peak potential shifts to negative values, also the current peak was more increased by adding MWCNTs as a modifier and the peak potential slightly shifted to more negative values. This means that the modified electrode presents the electrocatalytic activity to AA. The increase of current peak indicates that a higher amount of species was oxidized, while the shift in potential shows a higher facility in oxidizing these species.

The overall reaction of AA oxidation expressed by the following reaction:

$$
\mathrm{C}_{6} \mathrm{H}_{8} \mathrm{O}_{6} \text { (Ascorbic acid) } \rightarrow \mathrm{C}_{6} \mathrm{H}_{6} \mathrm{O}_{6} \text { (Dehydroascorbate) + }
$$$$
2 \mathrm{H}^{+}+2 \mathrm{e}^{-}
$$ 


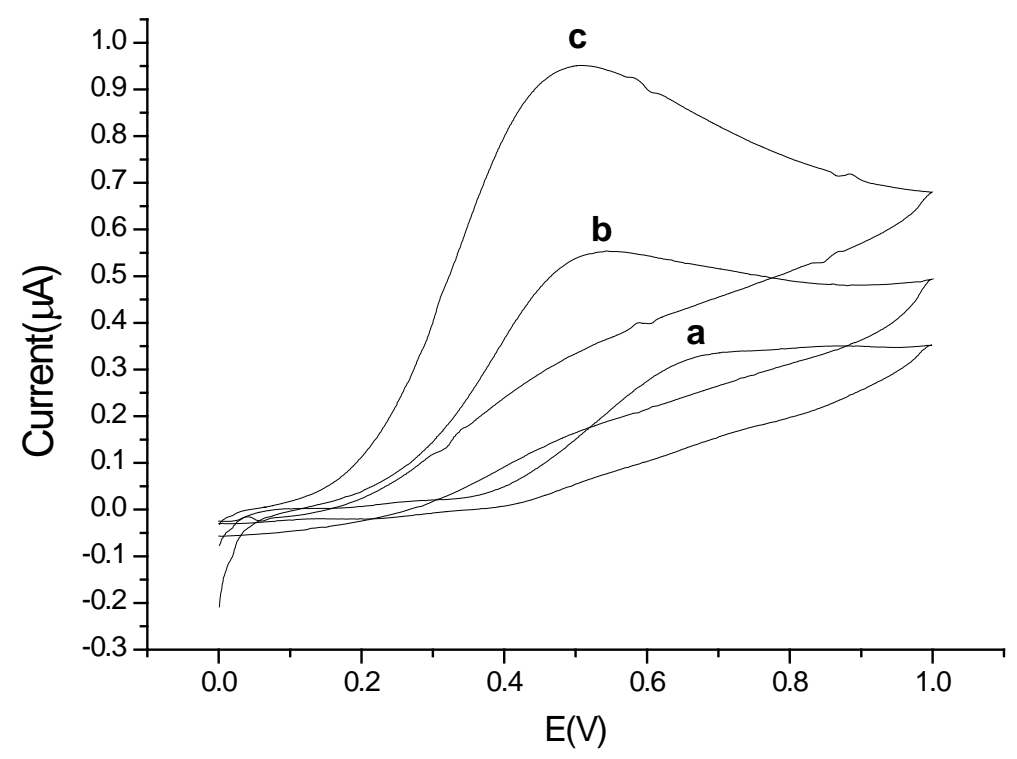

Figure 1. cyclic voltammograms of $2 \times 10^{-5}$ mole of AA at (a)_ unmodified CPE ( b)_ modified CPE with silica gel, (c)_ modified CPE with Silica gel_MWCNTs

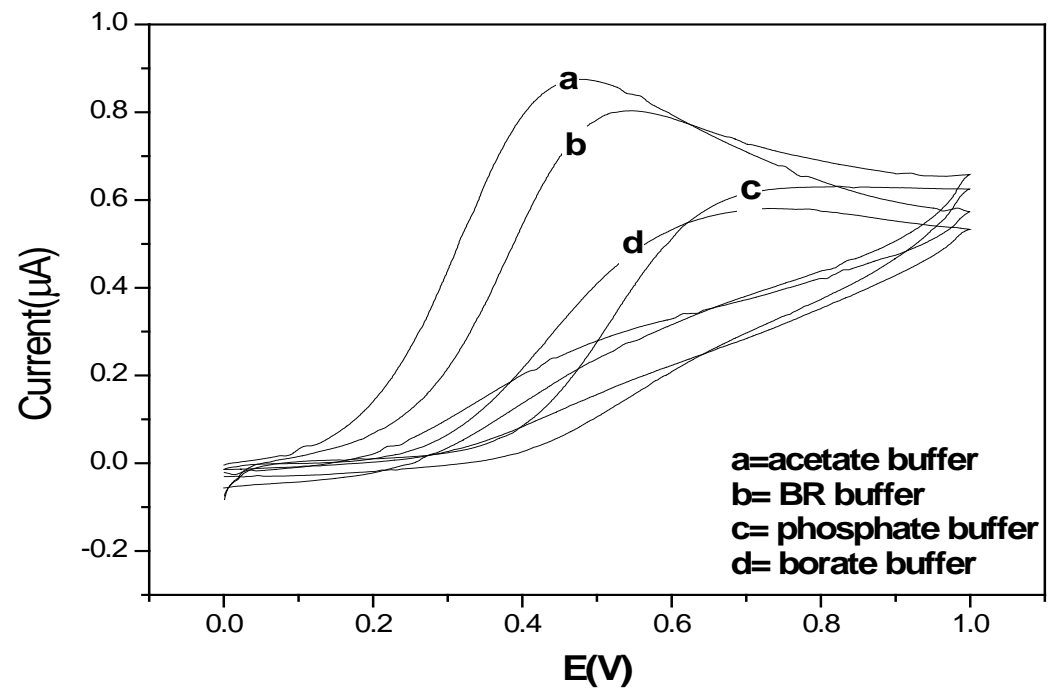

Figure 2. Cyclic voltammograms of $2 \times 10^{-5}$ mole of AA in different supporting electrolytes using Silica gel_MWCNTs/ CPE

\subsection{Effect of the Supporting Electrolyte:}

The effect of supporting electrolyte was examined on the oxidation peak of AA at the same conditions in different supporting electrolytes, Sodium acetate buffer, sodium phosphate buffer, borate buffer and B-R buffer have a responsibility toward the electro-oxidation peak of AA Figure (2). The shape and the height of the oxidation peak of AA were taken into consideration in choosing the suitable supporting electrolyte. The results showed that the suitable oxidation peak (shape and height) of AA is in Acetate buffer.

\subsection{Effect of $\mathrm{pH}$ :}

The influence of $\mathrm{pH}$ on the oxidation of ascorbic acid was investigated in the range $\mathrm{pH}=(2-9)$. Voltammograms were obtained using $5 \times 10^{-5} \mathrm{M}$ AA at a scan rate of $50 \mathrm{mV}$ $\mathrm{s}^{-1}$. The results indicated that the peak potential, Ep, shifts to more negative values with increasing $\mathrm{pH}$ which suggests that the acidic dissociation of ascorbic acid occurs at or before the rate determining step [6]. Also, the linear sweep voltammetric peak heights for the oxidation of AA are strongly affected by the solution $\mathrm{pH}$ as shown in Figure (3 a,b): 


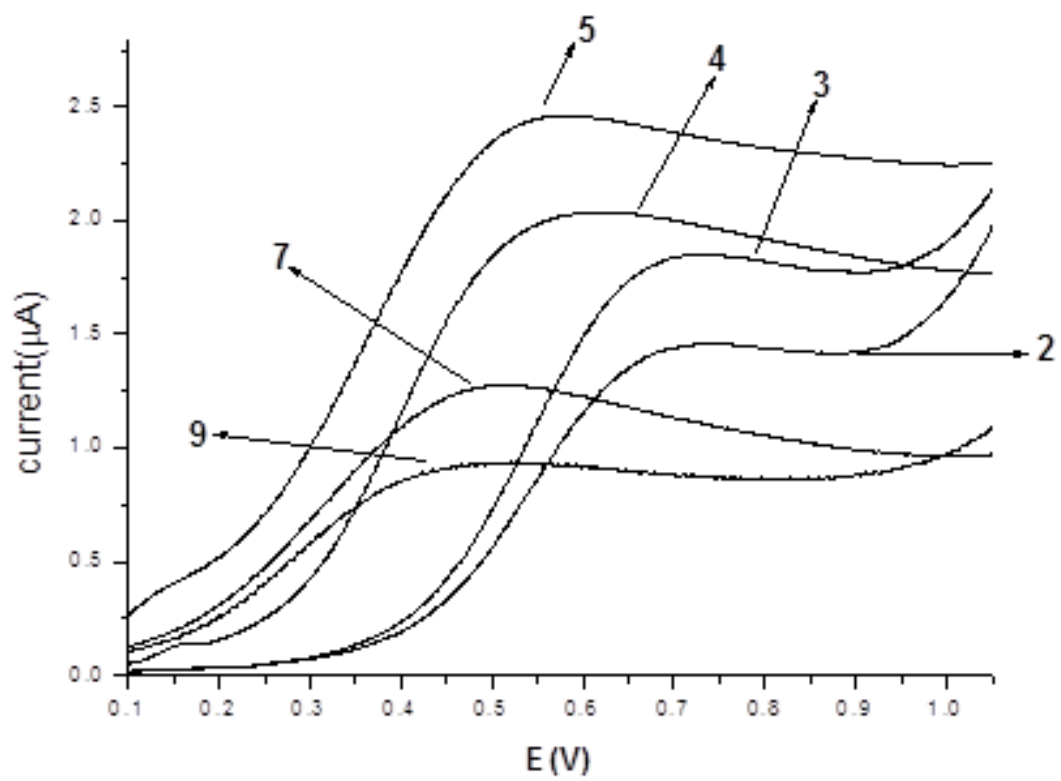

Figure 3.a. Influence of $\mathrm{pH}$ on the peak current of AA in $0.10 \mathrm{M}$ acetate buffer at scan rate $50 \mathrm{mV} / \mathrm{s}$

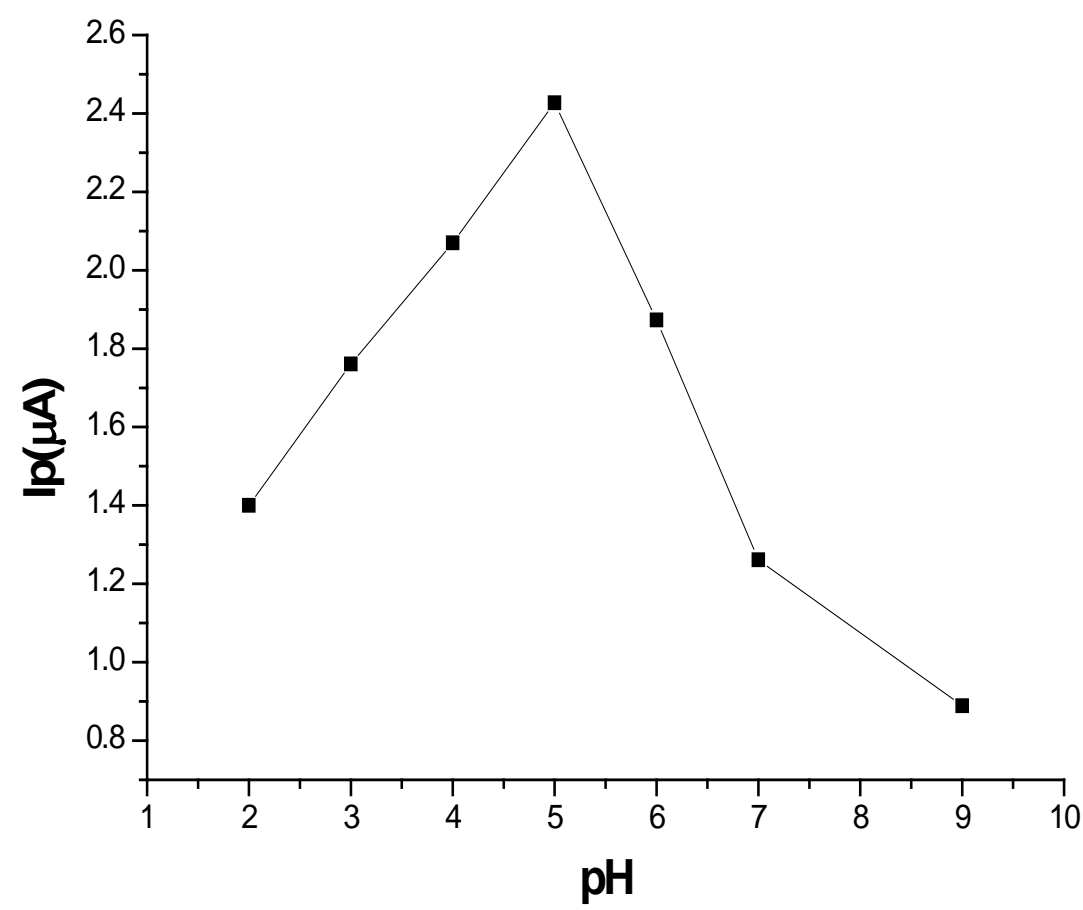

Figure 3.b. Dependence of the peak current of $\left(5 \times 10^{-5} \mathrm{M}\right) \mathrm{AA}$ on the $\mathrm{pH}$ of the supporting electrolyte

The best $\mathrm{pH}$ value was chosen at $\mathrm{pH}=5$. This $\mathrm{pH}$ is suitable for better stability of ascorbic acid because it has been suggested that for maximum stability, ascorbic acid solutions should be buffered to $\mathrm{pH}=5.4$ [28]. A plot of peak potential versus $\mathrm{pH}$ gave a straight line Figure (4):

$$
\mathrm{Ep}(\mathrm{mV})=790-47.3 \mathrm{pH}
$$

with a slope of $47.3(\mathrm{mV} / \mathrm{pH})$, this value suggests an equal number of electrons and protons in the AA oxidation [29]. These displacements are in accordance with the ones reported in the literature for AA oxidation [8]. 


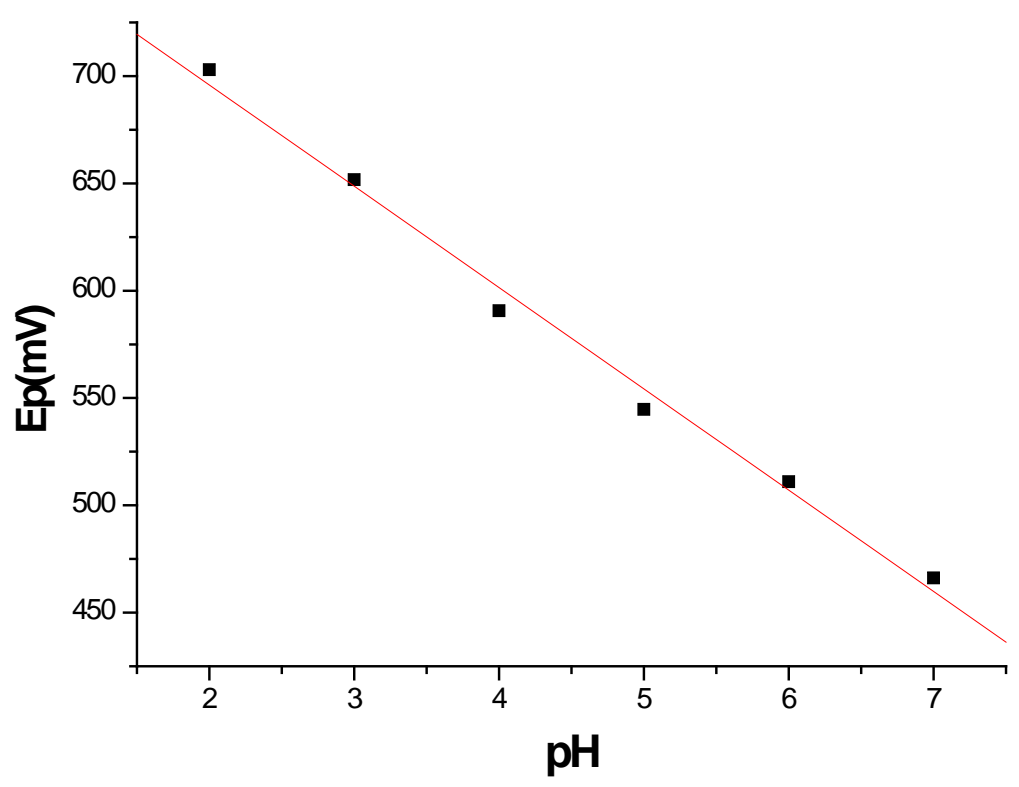

Figure 4. Dependence of the peak potential of $\left(5 \times 10^{-5} \mathrm{M}\right) \mathrm{AA}$ on the $\mathrm{pH}$ of the supporting electrolyte

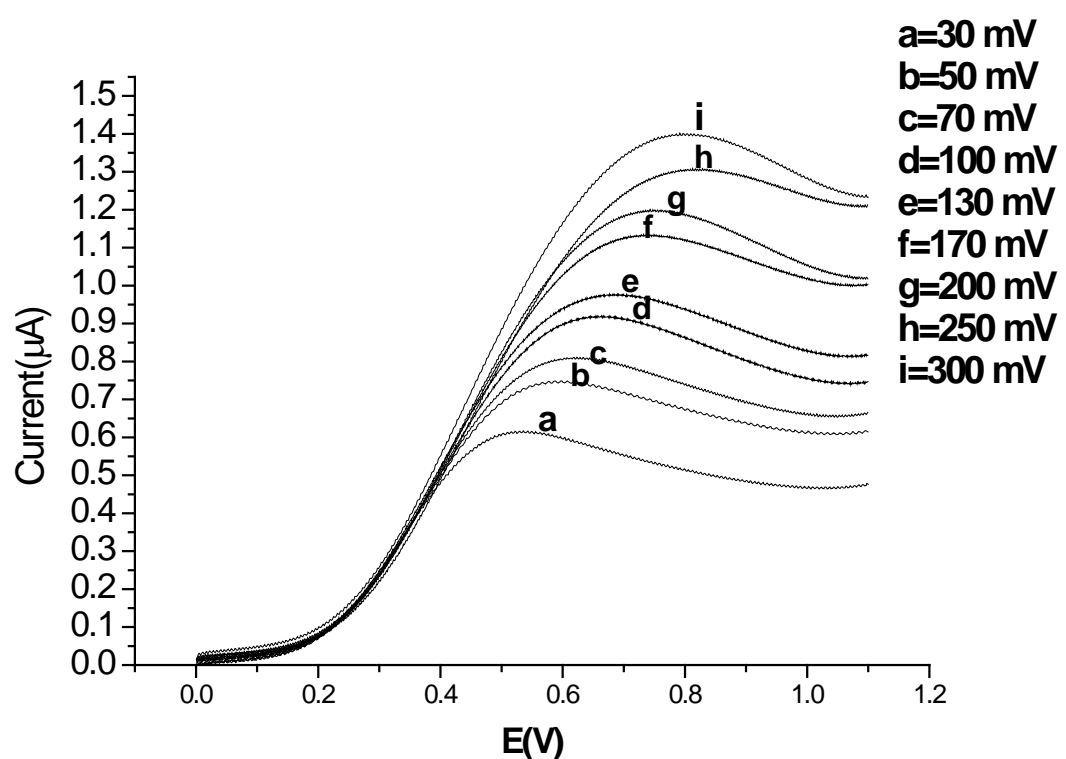

Figure 5. The effect of scan rate from ( 5 to $300 \mathrm{mVIS}$ ) on the peak current of $\left(5 \times 10^{-6} \mathrm{M}\right)$ AA in acetate buffer ( $\left.\mathrm{pH}=5.0\right)$, using Silica gel_MWCNTs/CPE

\subsection{Effect of Scan rate:}

The electrooxidation peak $\left(2 \times 10^{-5} \mathrm{M}\right)$ of AA in acetate buffer at $\mathrm{pH}=5.0$ using Silica gel/MWCNTs CPE was studied at different scan rate varying from 5 to $300 \mathrm{mV} / \mathrm{s}$. By increasing scan rate the oxidation peak current increased $[30,31]$ and shifted slightly to the positive side as shown in Figure (5), but at scan rate, more than 250 $\mathrm{mV} / \mathrm{s}$ the peak shape was distorted, especially at high concentrations of AA. As indicated in Figure (6), the plots of peak currents against the square root of the scan rates exhibited linear relationship:

$$
\text { Ip }(\mu \mathrm{A})=0.39+0.06 v^{0.5}(\mathrm{mV} / \mathrm{s})^{0.5} \quad\left(\mathrm{r}^{2}=0.998\right) .
$$

showing that the electrocatalytic oxidation of AA was diffusion control [29]. A plot of the logarithm of peak current versus the logarithm of scan rate Figure (7) gave a straight line with a slope of 0.43 :

$$
\log (\mathrm{Ip})=0.83-0.43 \times \log (v) \quad\left(r^{2}=0.997\right) .
$$

this slope is very close to the theoretical value of 0.5 , which is expected for a diffusion controlled process [32].also the linear displacement of the peak potential(Ep) with the increase of the scan rate Figure (8), according to the following equation:

$$
\mathrm{Ep}(\mathrm{mV})=423+70 \times \log (\mathrm{v}) \quad\left(\mathrm{r}^{2}=0.996\right) \text { [33] }
$$

the total number of participate electros was calculated from laviron eq $\Delta \mathrm{E} / \Delta \log (v)=59 / \mathrm{n} \alpha$, ( where $\alpha$ is the electron transfer coefficient $)$ and found to be (1.96 2). 


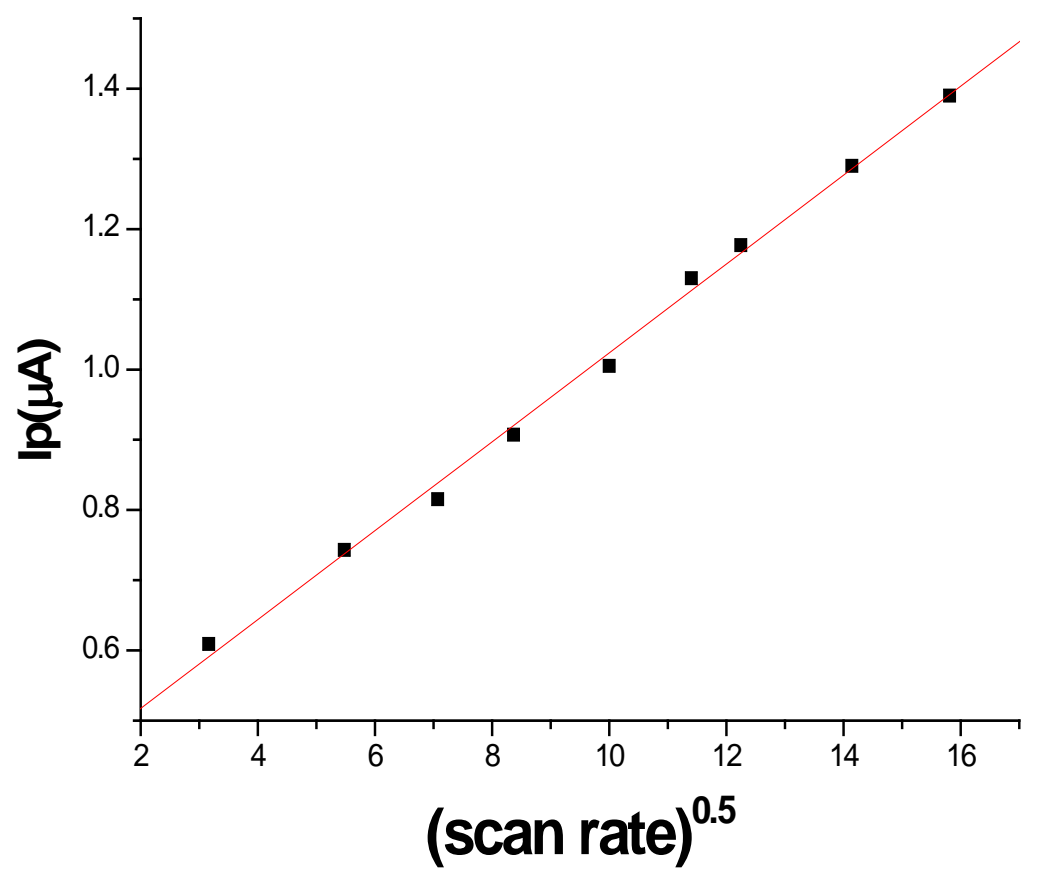

Figure 6. The relation between the peak current of $\left(5 \times 10^{-6} \mathrm{M}\right)$ of AA in acetate buffer $(\mathrm{pH}=5.0)$ using Silica gel_MWCNTs/CPE with the square root of scan rate

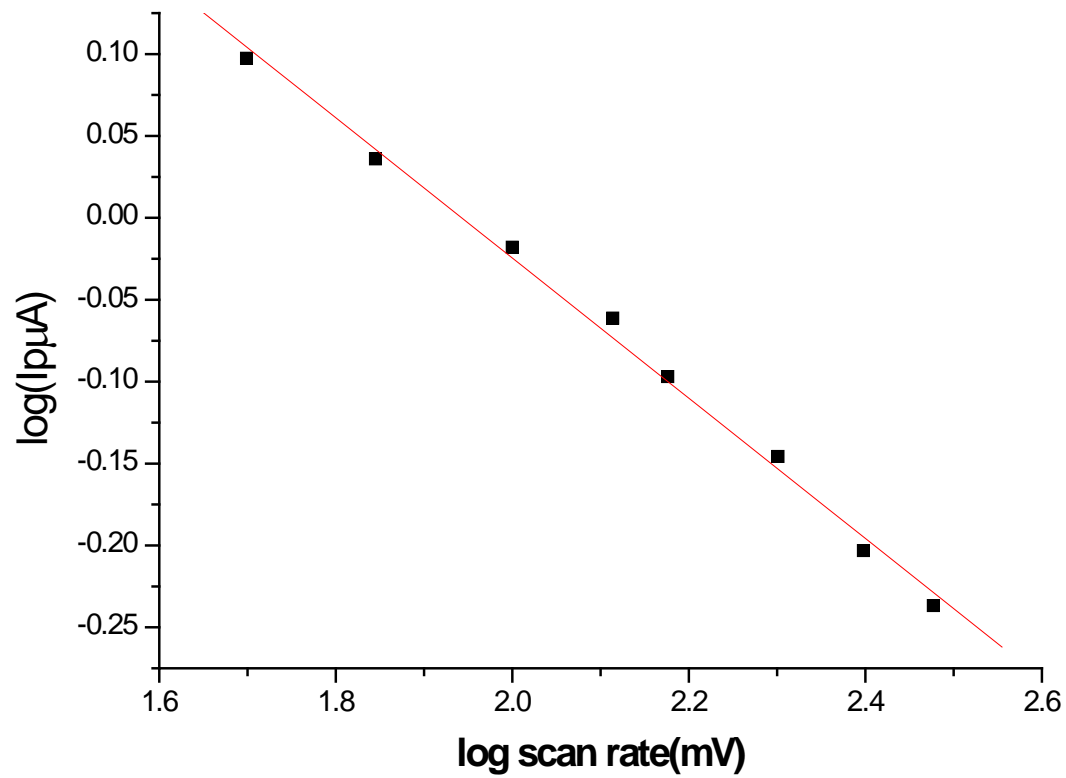

Figure 7. The relation between $\log$ peak current of $\left(5 \times 10^{-6} \mathrm{M}\right)$ of AA in acetate buffer $(\mathrm{pH}=5.0)$ using Silica gel_MWCNTs/CPE with log scan rate 


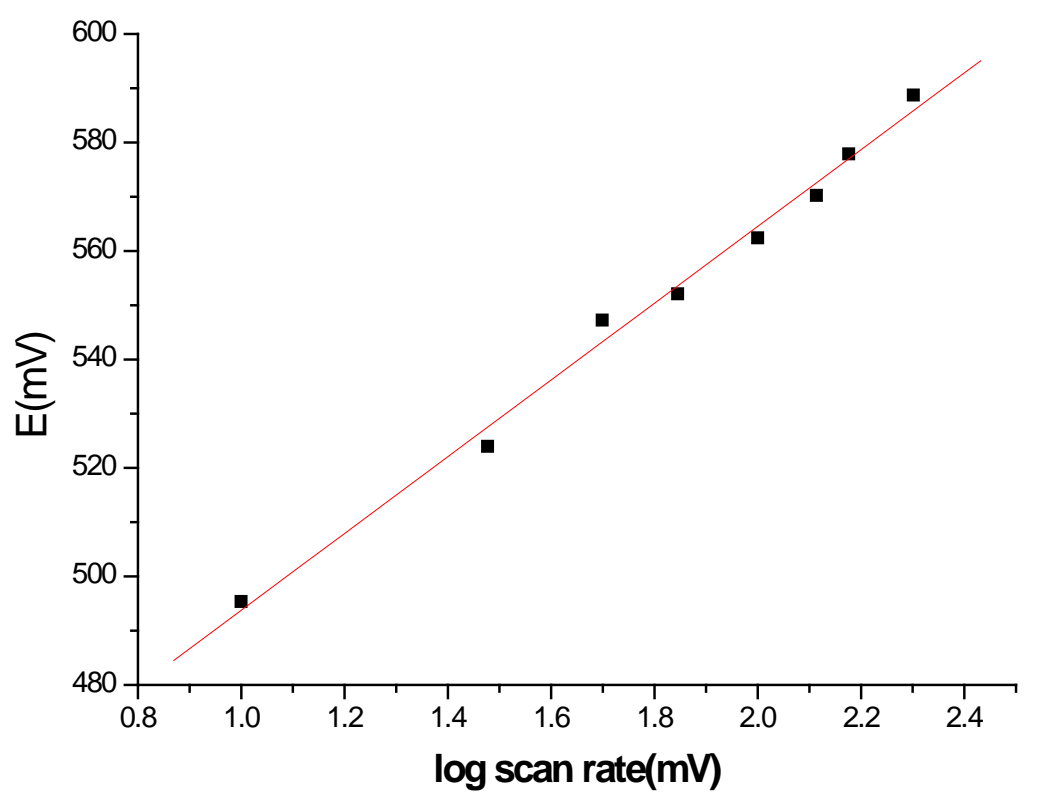

Figure 8. The relation between the peak potential $(\mathrm{mV})$ of $\left(5 \times 10^{-6} \mathrm{M}\right)$ AA in acetate buffer $(\mathrm{pH}=5.0)$ using Silica gel_MWCNTs/CPE with log scan rate $(\mathrm{mV})$

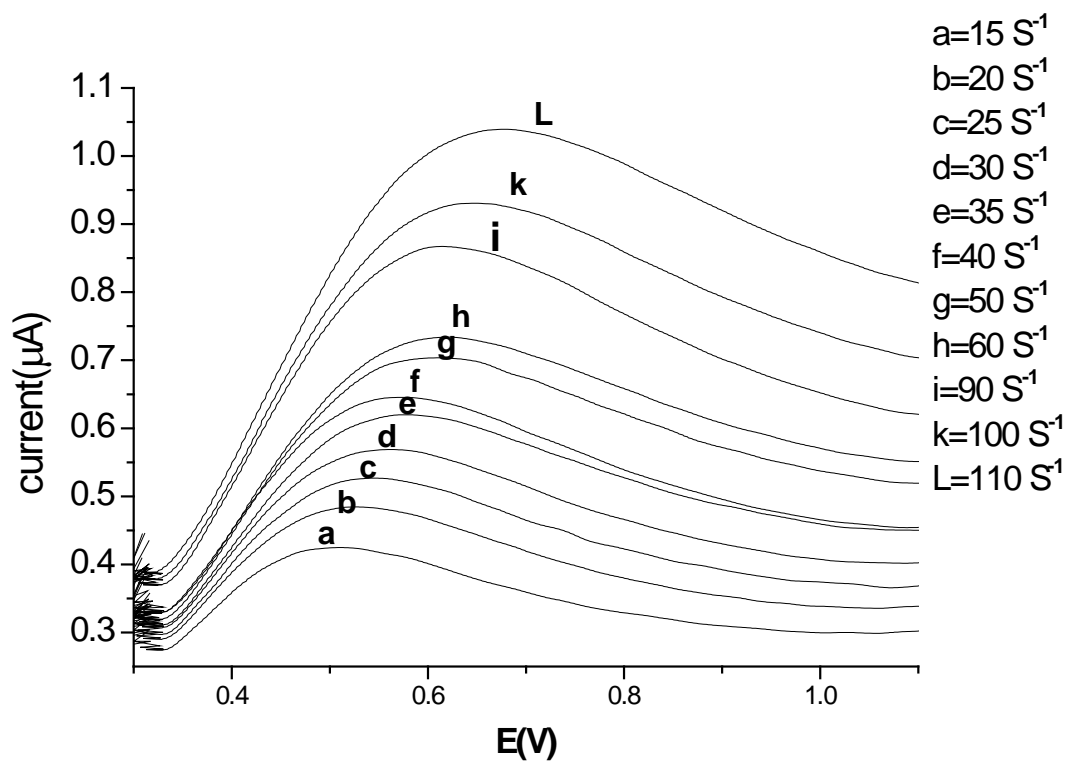

Figure 9. The effect of frequency $\left(\mathrm{S}^{-1}\right)$ on the peak current of $\left(2 \times 10^{-6} \mathrm{M}\right) \mathrm{AA}$ in acetate buffer $(\mathrm{pH}=5.0)$ using Silica gel_MWCNTs/CPE

\subsection{Electroanalytical determination of AA:}

Due to its speed and higher sensitivity relative to other pulse voltammetric techniques, SWV was chosen for the development of the electroanalytical methodology for AA analysis. The effect of SWV frequency in the peak current was investigated in the range of 10 to $150 \mathrm{~s}^{-1}$ Figure (9). The good linearity between Ip vs $\mathrm{f}$ as shown in Figure (10) until $100 \mathrm{~s}^{-1}$ with the linear regression equation:

$$
\text { Ip }(\mu \mathrm{A})=0.415+0.0065 \times \mathrm{f}\left(\mathrm{s}^{-1}\right)
$$

confirms the irreversible nature of the AA oxidation process which is in accordance with the SWV theory [34]. Higher than a frequency of $110 \mathrm{~s}^{-1}$ we got distorted peaks, so the frequency of $100 \mathrm{~s}^{-1}$ was chosen for analytical determination of AA, also the linear displacement of the peak potential (Ep) with the increase of the frequency Fig (11), according to the equation:

Ep $(\mathrm{mV})=424.6+74 \times \log \mathrm{f}\left(\mathrm{s}^{-1}\right)$

the $n \alpha$ value was calculated according to the equation:

$$
\Delta \mathrm{E} / \Delta \log (\mathrm{f})=59 / \mathrm{n} \alpha
$$

resulting in a value close to 0.78 and $\alpha=0.4$ very close to that calculated previously using LSV. The pulse high and the pulse amplitude were also varied and the best values for both parameters were fixed at $6 \mathrm{mV}$ and $30 \mathrm{mV}$, respectively. 


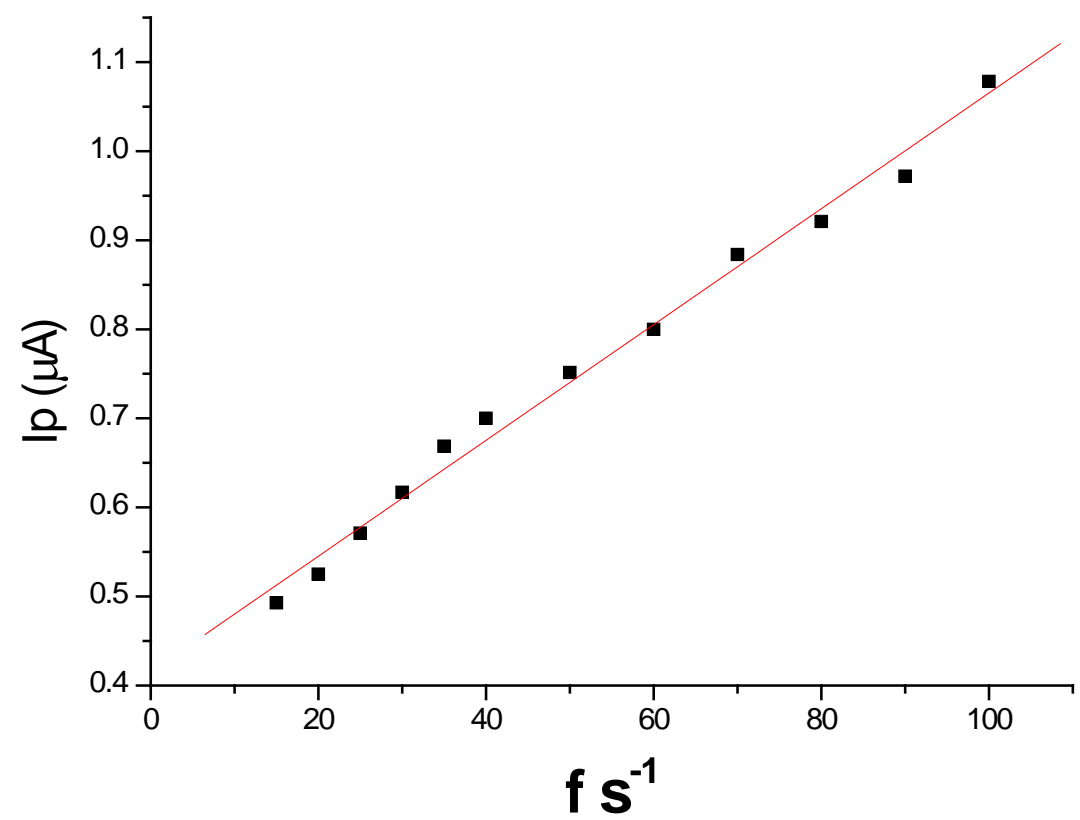

Figure 10. The relation between the peak current $(\mu \mathrm{A})$ and frequency $\left(\mathrm{S}^{-1}\right)$ of $\left(2 \times 10^{-6} \mathrm{M}\right)$ AA using SWV at Silica gel_MWCNTs/CPE

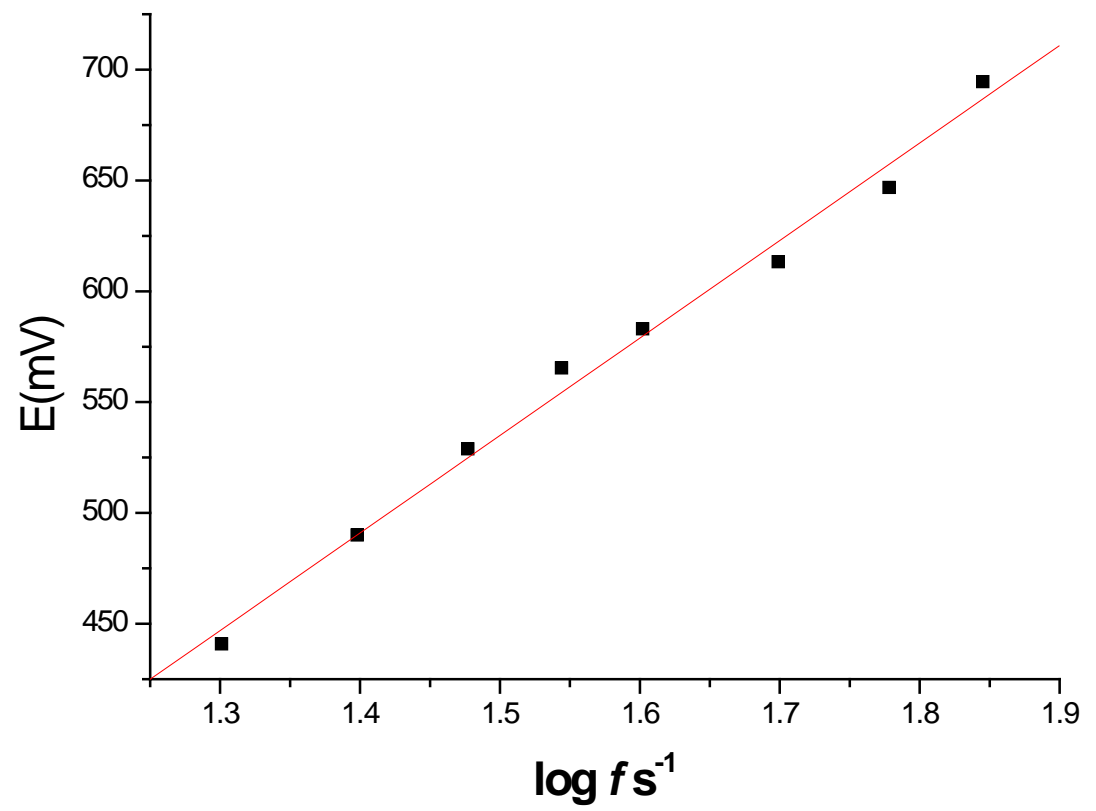

Figure 11. The relation between the peak potential $(\mathrm{mV})$ and $\log$ frequency $\left(\mathrm{S}^{-1}\right)$ of $\left(2 \times 10^{-6} \mathrm{M}\right)$ AA using SWV at Silica gel_MWCNTs/CPE

Influence of AA concentration on the oxidation peak current was studied over the range $\left(5 \times 10^{-8}-4 \times 10^{-6}\right.$ Mole) in acetate $(\mathrm{pH}=5.0)$, the peak current at a potential of $+0.5 \mathrm{~V}$ increased proportionally with the AA concentration fig (12) to yield a highly linear calibration plot fig (13):

$$
\text { ip }(\mu \mathrm{A})=0.302 \mathrm{C}(\mu \mathrm{M})+0.8167 \quad\left(\mathrm{r}^{2}=0.997, \mathrm{n}=10\right)
$$

The limit of detection (LOD) and limit of quantification
(LOQ) were calculated using the following equations [35]:

$$
\mathrm{LOD}=3 \mathrm{~s} / \mathrm{m}, \mathrm{LOQ}=10 \mathrm{~s} / \mathrm{m}
$$

where is the standard deviation of the peak current (three runs) of the lowest concentration of the linearity range and $\mathrm{m}$ is the slope of the related calibration equation. LOD and LOQ were calculated as $1.07 \times 10^{-8} \mathrm{M}$ and $3.5 \times 10^{-8} \mathrm{M}$, respectively. 


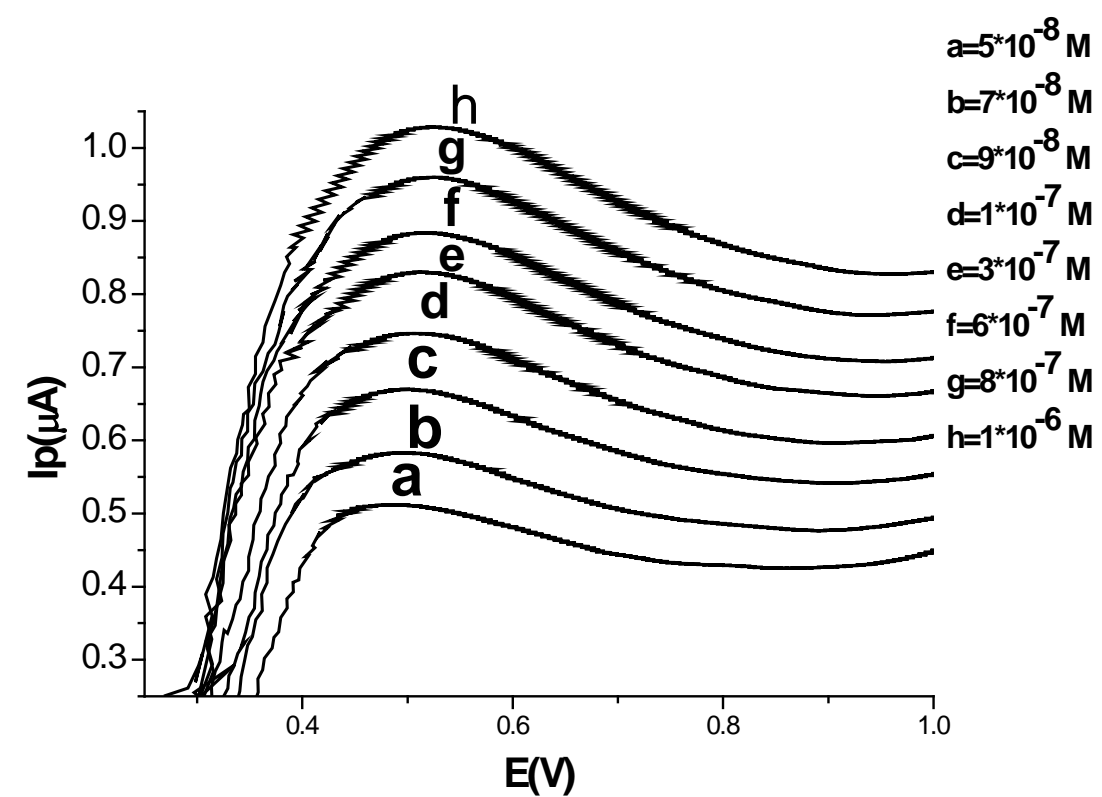

Figure 12. SWV for different concentrations of AA at Silica gel_MWCNTs/ PE

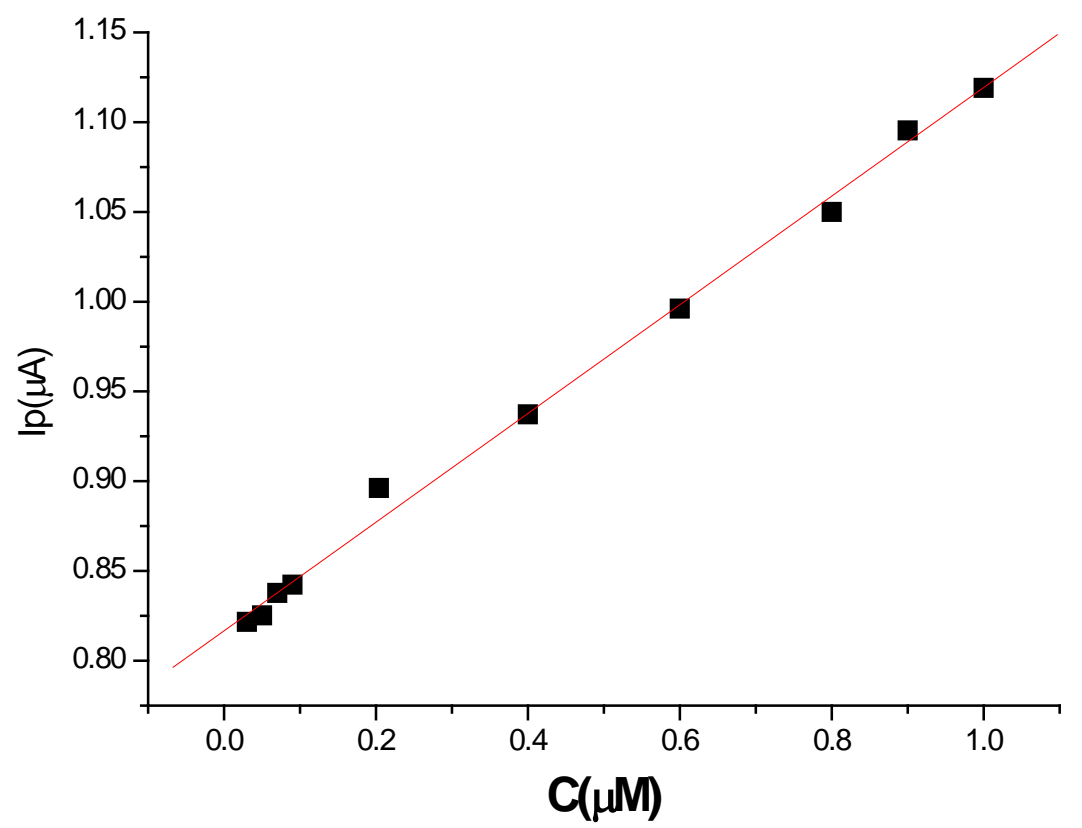

Figure 13. Calibration Curve of AA at Silica gel_MWCNTs/CPE

Table 1. Indicates a comparison of the reported values comparable to the obtained value in the present work:

\begin{tabular}{|c|c|c|c|}
\hline $\begin{array}{c}\text { Voltammetric } \\
\text { Technique }\end{array}$ & Working Electrode & Detection limit & Reference \\
\hline CV & $\begin{array}{c}\text { Poly(aniline-co-m-ferrocenyl aniline) Modified Glassy } \\
\text { Carbon Electrode }\end{array}$ & $2 \times 10^{-6} \mathrm{M}$ & {$[10]$} \\
\hline CV & $\begin{array}{c}\text { polypyrrole/ferrocyanide films modified carbon } \\
\text { Paste electrode. }\end{array}$ & $5.8 \times 10^{-5} \mathrm{M}$ & {$[11]$} \\
\hline LSV & Carbon Paste Electrode & $1 \times 10^{-6} \mathrm{M}$. & {$[36]$} \\
\hline DPV & Helical Carbon Nanotubes (HCNTs). & $1.2 \times 10^{-7} \mathrm{M}$ & {$[12]$} \\
\hline DPV & Modified Carbon Paste Electrode with 2, 7-bis (Ferrocenyl ethynyl) \\
Fluorene-9-one. & $4.2 \times 10^{-6} \mathrm{M}$ & {$[13]$} \\
\hline DPV & Calixarene Modified Carbon Paste Electrodes & $3 \times 10^{-8} \mathrm{M}$. & {$[15]$} \\
\hline SWV & Mn-SnO2nanoparticles modified glassy carbon electrode. & $5.9 \times 10^{-8} \mathrm{M}$. & {$[37]$} \\
\hline SWV & Silica gel_MWCNTs/CPE & $1.2 \times 10^{-8} \mathrm{M}$ & Present Work \\
\hline
\end{tabular}




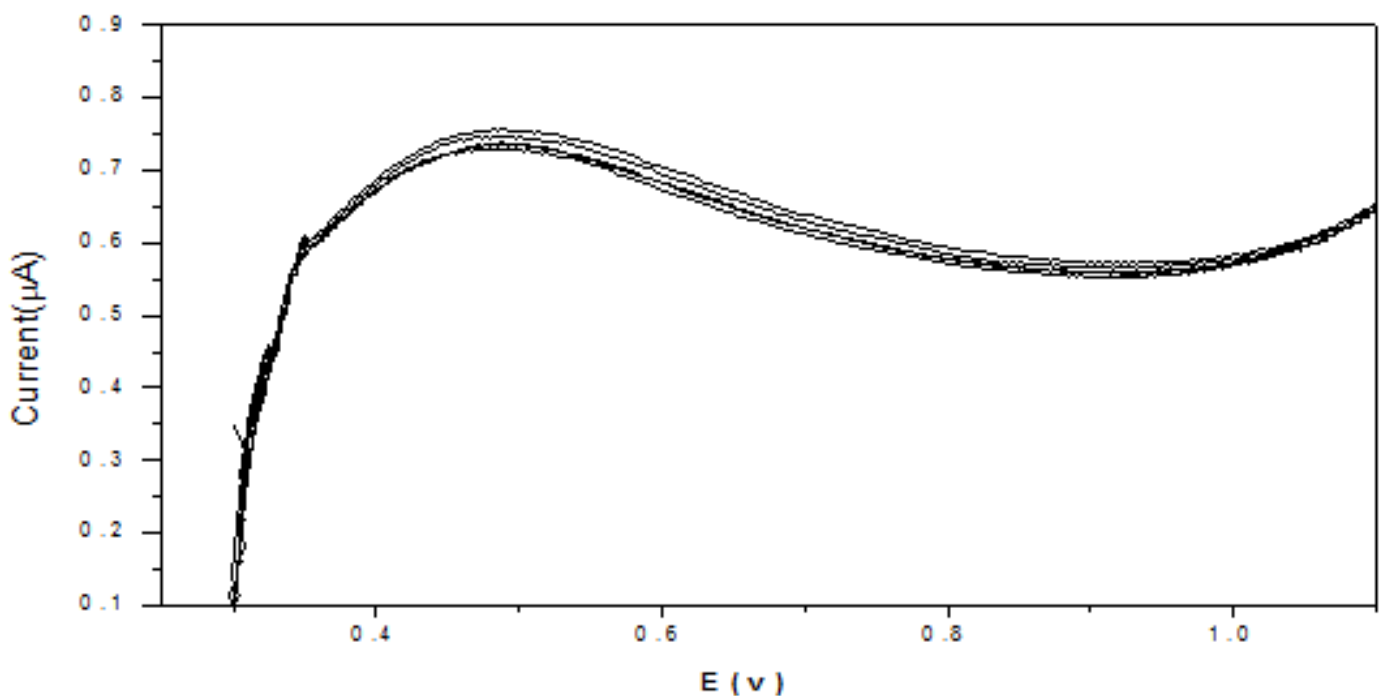

Figure 14. The reproducibility of the results was examined by six successive measurements of $1 \times 10^{-6} \mathrm{M}$ of AA in acetate buffer ( $\left.\mathrm{pH}=5.0\right)$ using $\operatorname{SWV}\left(\mathrm{f}=100 \mathrm{~s}^{-1}\right)$ at CPE modified by Silica gel- MWCNTs

\subsection{Reproducibility}

The reproducibility of the results was examined by six successive measurements of $1 \times 10^{-6} \mathrm{M}$ AA under the optimum conditions figure(14) The relative standard deviation (RSD) was calculated and it was found to be $1.08 \%$.

\subsection{Analytical Application}

This proposed method was used to determine ascorbic acid in orange fruits applying of the optimum conditions selected before. The Recovery of AA was calculated by comparing the concentration obtained from the spiked mixtures with those of the pure AA using the following eq:

$$
\text { Recovery\%=((QDET-QP) } \times 100) / \mathrm{QADD}
$$

Where $\mathrm{Q}_{\mathrm{DET}}$ represents $\mathrm{mM}$ of ascorbic acid determined in the extracted sample, QP represents $\mathrm{mM}$ of ascorbic acid previously present in the extracted sample and $\mathrm{Q}_{\mathrm{ADD}}$ is $\mathrm{mM}$ of AA added to the extracted sample. In Table 1, the results of the analysis of spiked samples of orange and lemon fruits are shown. It was found that AA amount can be quantitatively recovered by the proposed method, is thus a guarantee of the accuracy of the voltammetric determination of AA in orange and lemon fruits.

Table 2. Determination of the content of AA in the orange and lemon fruit samples

\begin{tabular}{|c|c|c|c|}
\hline \multirow{2}{*}{$\begin{array}{c}\text { Orange } \\
\text { extracted } \\
\text { sample }\end{array}$} & $\mathrm{Q}_{\mathrm{DET}}-\mathrm{Q}_{\mathrm{P}}$ of AA & $\mathrm{Q}_{\mathrm{ADD}}$ of AA & Recovery\% \\
\cline { 2 - 4 } & $0.0288 \mathrm{mM}$ & $0.03 \mathrm{mM}$ & $96 \%$ \\
\cline { 2 - 4 } & $0.051 \mathrm{mM}$ & $0.05 \mathrm{mM}$ & $102 \%$ \\
\hline \multirow{2}{*}{$\begin{array}{c}\text { Lemon } \\
\text { extracted } \\
\text { sample }\end{array}$} & $\mathrm{Q}_{\mathrm{DET}}-\mathrm{Q}_{\mathrm{P}}$ of AA & $\mathrm{Q}_{\mathrm{ADD}}$ of AA & Recovery\% \\
\cline { 2 - 4 } & $0.0292 \mathrm{mM}$ & $0.03 \mathrm{mM}$ & $97.3 \%$ \\
\cline { 2 - 4 } & $0.0497 \mathrm{mM}$ & $0.05 \mathrm{mM}$ & $99.4 \%$ \\
\hline
\end{tabular}

\section{Conclusions}

A new modified CPE with silica gel/CNTs was successfully used in combination with the SWV technique to develop a novel and alternative electroanalytical method for AA determination in the plant samples. The prepared silica gel/ CNTs CPE electrode combines the advantages of both Silica gel and CNTs, exhibiting large surface area, and good biocompatibility, as well as favorable electrochemical properties. It showed good electrochemical reversibility, fast electronic transfer kinetics and favorable electrocatalytic performance relative to AA. High sensitivity, low detection limits, and good stability were achieved on the prepared composite electrode based on silica gel/CNTs CPE could be used as a promising platform for electrochemical studies of AA.

\section{REFERENCES}

[1] Ascorbate function and associated transport systems in plants, Plant Physiol. Biochem. 38 (2000) 531-540.

[2] G.M. Pastori, G. Kiddle, J. Antoniw, S. Bernard, S. Veljovic-Jovanovic, P.J. Verrier, G. Noctor, C.H. Foyer, Leaf Vitamin C Contents Modulate Plant Defense Transcripts and Regulate Genes That Control Development through Hormone Signaling, Plant Cell Online. 15 (2003).

[3] N.A. Anjum, S.S. Gill, R. Gill, M. Hasanuzzaman, A.C. Duarte, E. Pereira, I. Ahmad, R. Tuteja, N. Tuteja, Metal/metalloid stress tolerance in plants: role of ascorbate, its redox couple, and associated enzymes, Protoplasma. 251 (2014) 1265-1283.

[4] Y. Zhang, Biological Role of Ascorbate in Plants, in Springer, New York, NY, 2013: pp. 7-33. 
[5] D.R. Gallie, L-ascorbic Acid: a multifunctional molecule supporting plant growth and development., Scientifica (Cairo). 2013 (2013) 795964.

[6] M.J. Aguirre, M. Isaacs, F. Armijo, N. Bocchi, J.H. Zagal, Catalytic Electrooxidation of 2 - Mercaptoethanol on Perchlorinated Iron Phthalocyanine Adsorbed on a Graphite Electrode, Electroanalysis. 10 (1998) 571-575.

[7] L.A. Pachla, D.L. Reynolds, P.T. Kissinger, Analytical methods for determining ascorbic acid in biological samples, food products, and pharmaceuticals., J. Assoc. Off. Anal. Chem. 68 (1985) 1-12.

[8] A. Nezamzadeh, M.K. Amini, H. Faghihian, Square-Wave Voltammetric Determination of Ascorbic Acid Based on its Electrocatalytic Oxidation at Zeolite-Modified Carbon-Paste Electrodes, Int.J. Electrochem. Sci. 2 (2007) 583-594.

[9] H.M. Rageh, M.M. Abou-Krisha, A.M. Abo-Bakr, M. Abd-Elsabour, Electrochemical Behavior and the Detection Limit of Ascorbic Acid on a Pt Modified Electrode, Int. J. Electrochem. Sci. 10 (2015) 4105-4115.

[10] S. Chairam, W. Sriraksa, M. Amatatongchai, E. Somsook, Electrocatalytic Oxidation of Ascorbic Acid Using a Poly(aniline-co-m-ferrocenylaniline) Modified Glassy Carbon Electrode, Sensors. 11 (2011) 10166-10179.

[11] Jahan-BakhshRaoof,RezaOjani,SaharRashid-Nadimi, Preparation of polypyrrole/ferrocyanide films modified carbon paste electrode and its application on the electrocatalytic determination of ascorbic acid, Electrochim. Acta. 49 (2004) 271-280.

[12] P. Gai, H. Zhang, Y. Zhang, W. Liu, G. Zhu, X. Zhang, J. Chen, Simultaneous electrochemical detection of ascorbic acid, dopamine and uric acid based on nitrogen doped porous carbon nanopolyhedra, J. Mater. Chem. B. 1 (2013) 2742. doi:10.1039/c3tb20215a.

[13] J. B. Raoof, R. Ojani, H. Beitollahi, Electrocatalytic Determination of Ascorbic Acid at Chemically Modified Carbon Paste Electrode with 2, 7-bis (Ferrocenyl ethynyl) Fluoren-9-one, Int. J. Electrochem. Sci. 2 (2007) 534-548.

[14] M.R. Ganjali, F.G. Nejad, H. Beitollahi, S. Jahani, M. Rezapour, B. Larijani, Highly Sensitive Voltammetric Sensor for Determination of Ascorbic Acid Using Graphite Screen Printed Electrode Modified with ZnO/Al 2 O 3 Nanocomposite, Int. J. Electrochem. Sci. 12 (2017) 32313240 .

[15] V. Ijeri, M. Algarra, A. Martins, Electrocatalytic Determination of Vitamin C Using Calixarene Modified Carbon Paste Electrodes, Electroanalysis. 16 (2004) 20822086.

[16] M. Javanbakht, S. Eynollahi Fard, M. Abdouss, A. Mohammadi, M. Reza Ganjali, P. Norouzi, L. Safaraliee, A Biomimetic Potentiometric Sensor Using Molecularly Imprinted Polymer for the Cetirizine Assay in Tablets and Biological Fluids,Electroanalysis. 20 (2008) 2023-2030.

[17] M. Javanbakht, M.R. Ganjali, P. Norouzi, A. Badiei, A. Hasheminasab, M. Abdouss, Carbon Paste Electrode Modified with Functionalized Nanoporous Silica Gel as a New Sensor for Determination of Silver Ion, Electroanalysis. 19 (2007) 1307-1314.
[18] M.R. Ganjali, H. Khoshsafar, A. Shirzadmehr, M. Javanbakht, F. Faridbod, Improvement of Carbon Paste Ion Selective Electrode Response by Using Room Temperature Ionic Liquids (RTILs) and Multi- Walled Carbon Nanotubes (MWCNTs),Int. J. Electrochem. Sci. 4 (2009) 435-443.

[19] A.B. Moghaddam, M.R. Ganjali, R. Dinarvand, T. Razavi, S. Riahi, S. Rezaei-Zarchi, P. Norouzi, Fabrication and electrochemical behavior of single-walled carbon nanotube/graphite-based electrode, Mater. Sci. Eng. C. 29 (2009) 187-192.

[20] B. Rezaei, S. Damiri, Multiwalled Carbon Nanotubes Modified Electrode as a Sensor for Adsorptive Stripping Voltammetric Determination of Hydrochlorothiazide, IEEE Sens. J. 8 (2008) 1523-1529.

[21] M. Siswana, K.I. Ozoemena, T. Nyokong, Electrocatalytic Detection of Amitrole on the Multi-Walled Carbon Nanotube - Iron (II) tetra-aminophthalocyanine Platform, Sensors. 8 (2008) 5096-5105.

[22] G. Li, H. Xu, W. Huang, Y. Wang, Y. Wu, R. Parajuli, A pyrrole quinoline quinone glucose dehydrogenase biosensor based on screen-printed carbon paste electrodes modified by carbon nanotubes, Meas. Sci. Technol. 19 (2008) 65203.

[23] A. Walcarius, C. Despas, J. Bessiere, Selective monitoring of $\mathrm{Cu}((\mathrm{II}))$ species using a silica modified carbon paste electrode, in: Anal. Chim. Acta, Elsevier, 1999: pp. 79-89.

[24] D. Gamenara, G.A. Seoane, P. Saenz-Méndez, P.D. de María, Redox Biocatalysis: Fundamentals and Applications, Wiley-Interscience, 2012.

[25] A. Walcarius, J. Bessiere, Silica-modified carbon paste electrode for copper determination in ammoniacal medium, Electroanalysis. 9 (1997) 707-713.

[26] S.J. Malode, J.C. Abbar, N.P. Shetti, S.T. Nandibewoor,Voltammetric oxidation and determination of loop diuretic furosemide at a multi-walled carbon nanotubes paste electrode, Electrochim. Acta. 60 (2012) 95-101.

[27] S. Nojavan, F. Khalilian, F.M. Kiaie, A. Rahimi, A. Arabanian, S. Chalavi. Extraction and quantitative determination of ascorbic acid during different maturity stages of Rosa canina L. fruit, J. Food Compos. Anal. 21 (2008) 300-305.

[28] J.E.F. REYNOLDS, Martindale: the extra pharmacopoeia. 28th edition., Martindale Extra Pharmacopoeia. 28th Ed. (1982).

[29] R.A. de Toledo, C.M.P. Vaz, Microchem ,Use of a graphite-polyurethane composite electrode for electroanalytical determination of indole-3-acetic acid in soil samples, Microchem. J. 86 (2007) 161-165.

[30] S.A.M.K. Ansari, J.N. Sangshetti, N.D. Kokare, P.S. Wakte, D.B. Shinde, Indian Journal of Chemical Technology, Adsorpt. J. Int. Adsorpt. Soc. 17 (2010) 5-6. http://nopr.niscair.res.in/handle/123456789/9549 (accessed September 15, 2017).

[31] T.L. Kulova, A.M. Skundin, High-voltage materials for positive electrodes of lithium ion batteries (review), Russ. J. Electrochem. 52 (2016) 501-524. 
[32] D.K. Gosser, Cyclic Voltammetry: Simulation and Analysis of Reaction Mechanisms, New York VCH,. (n.d.) 43.

[33] A. Arranz, I. Dolara, S. Fernández De Betoño, J. María Moreda, A. Cid, J. Francisco Arranz, Electroanalytical study and square wave voltammetric techniques for the determination of $\beta$-blocker timolol at the mercury electrode, Anal. Chim. Acta. 389 (1999) 225-232.

[34] P.A.D. Edwardson, J. Pharm. Biomed. Square-wave voltammetry of an adsorbed reactant, J. Electroanal. Chem. Interfacial Electrochem. 248 (1988) 239-253.

[35] J. Pharm. Biomed Method validation in pharmaceutical analysis. Anal. 8 (1990) 929-933.doi:10.1016/0731-7085(9 0)80144-E.

[36] J. Lindquist, Voltammetric determination of ascorbic acid by use of a carbon paste electrode, Analyst. 100 (1975) 339. doi:10.1039/an9750000339.

[37] R. Ramachandran, T. W. Chen, S. M. Chen, G. Peter Gnana Kumar, M. Chinnasamy, N.B. Devi, T.-W. Tseng, Recent Progress and Perspective Design of Various Electrode Catalysts for the Simultaneous Determinations of Dopamine in the Presence of Ascorbic Acid and Uric Acid: A Review, Int. J. Electrochem. Sci. Int. J. Electrochem. Sci. 12 (2017) 1572-1588. 